REVIEW ARTICLE

\title{
Sleep and Sugar: Diabetes and associated sleep problems
}

Anuradha A Shah

Indian J Sleep Med 2009; 4.1, 1-3

S leep disturbances are common in diabetics. D iabetics report higher rates of insomnia, excessivedaytimeslepiness, and unpleasant sen sations in the legs that disturb sleep..$^{1,2} \mathrm{H}$ ence up to $71 \%$ of this population complain of poor sleep quality ${ }^{3}$ and high rates of hypnotic use. ${ }^{1}$

$M$ any factorscontributeto insomniain diabetics. In type 1 diabetes, rapid changes in glucose levels during sleep can causeawakenings. ${ }^{4}$ In individuals with type 2 diabetes, sleep disturbancesmay berelated to obesity or sleep apnea. Sleepdisordered breathing correlates highly with obesity in the diabetic population. ${ }^{5}$ A strong association also exists between obesity, impaired glucose tolerance, insulin resistanceand sleep-disordered breathing. ${ }^{5-7}$ The severity of sleepdisordered breathing, as measured by the apnea-hypopnea index, correlates with the severity of glucose intolerance, insulin resistance and diabetes. ${ }^{7,8} 0$ bstructive sleep apnea is the commonest type of sleep-disordered breathing. Patients with autonomic diabetic neuropathy may have central-typeapneas and periodic breathing. ${ }^{5}$

D iscomfort or pain can disturb sleep in patients with peripheral neuropathy. ${ }^{9}$ Sleep-onset and maintenance of insomnia can be caused by restless legs syndrome and periodic limb movements in diabetics with peripheral neuropathy. ${ }^{10} \mathrm{H}$ yperglycemia or hypoglycemia during the night and night sweats can contribute to disturbed sleep. .11

There is evidence that demonstrates that individuals with diabetesare at risk for poor sleep quality and that poor sleep is associated with insomnia, sleep-disordered breathing, restless legs syndrome besides chronic pain may exacerbate diabetes. Therefore, evaluation and management of patients with diabetes should includean assessment of sleep quality and sleep disorders.

Address for Correspondence:

Anuradha A Shah

MD (Med) DNB (Resp. Med) FCCP (USA)

anuradha.shah@pds.piramal.com

\section{Key questions to be asked}

Recognition that the etiology of sleep disruption in diabetes is often multifactorial, is essential:

1. D o you have difficulty falling or staying asleep?

2. Are you excessively sleepy during the day or fall asleep when you do not want to?

3. Do you snore or have you been told that you snore loudly?

4. D o you gasp for air or haveyou been told that you stop breathing during sleep?

5. Do you experience uncomfortable sensations in the legs in the evening that are relieved by movement?

6. Areyou a restless sleeper or haveyou been told that you kick during sleep?

After considering and ruling out medical and psychiatric causes of insomnia, a diagnosis of primary insomnia may be made. K eeping a sleep diary during a two-week period can provide a detailed assessment of sleep and wake patterns. The diagnosis of restless legs syndrome is usually made by the history and physical examination. H owever, when a diagnosis of sleep apnea is suspected, an overnight polysomnogram isusually required for diagnosis.

\section{Management of sleep disorders}

Succesfful management of sleep disorders often requires a multifaceted approach that not only provides relief of symptoms, but also treatment of the common comorbid conditions.

\section{O bstructive Sleep Apnea}

D iabetics who have obstructive sleep apnea, medical management includes weight loss, identification and 
treatment of anatomic and functional upper airway obstruction and nasal continuous positiveairway pressure. In addition to improving sleep quality and nocturnal hypoxemia, continuous positiveairway pressureuseimproves insulin sensitivity in patients with sleep apnea. ${ }^{12}$ M uch less information is available about effective treatments for periodic breathing and central-typeapneas in patients with autonomic neuropathy. Regular, moderate-intensity physical activity has shown to havea protective effect on both snoring and diabetes in overweight people. ${ }^{13}$ Effectivetreatment of sleep apneacan improveglucose regulation, insulin sensitivity as well asthedaytimefunction and quality of life of diabetics.

\section{Hypoglycemia}

In type 1 diabetics, autonomic responses to hypoglycemia are reduced during sleep. Patients with hypoglycemia during sleep showed improved sleep efficiency and increased slow wave sleep. ${ }^{4}$ It is probable that reduced sympatho-adrenal responses inhibit sympathetic and arousal responses to hypoglycemia in these patients. This reduction results in patients becoming substantially less likely to beawakened by hypoglycemia during thenight. ${ }^{14}$ Rapid changes in glucose, rather than absolute glucose levels, may be the catalyst for awakening from sleep. ${ }^{4} \mathrm{As}$ a result, nocturnal glucose levels should be closely monitored in type 1 diabetics, to prevent hypoglycemia during sleep.

\section{Peripheral neuropathies}

When parasthesias and pain are secondary to peripheral neuropathies, treatment should be focused on pain control. Treatment of pain symptoms for those with diabetic neuropathy may include analgesics, antidepressants (such as tricyclics and selective serotonin reuptake inhibitors (SSRIs]) or gamma-amino butyric acid (GABA) ergic agents (such as gabapentin or tiagabine) $^{15}$

\section{Restless Legs Syndrome}

D iabetic patients with restless legs syndrome often also have periodic limb movements during sleep. After evaluation for possiblecauses, such asiron deficiency or thyroid disease, dopamine agonist medications, benzodiazepines, and gabapentin are recommended. In severe cases, opiates may beused for relief of symptoms. In patients with low levels of ferritin, evaluation for sources of iron loss and iron replacement therapy isuseful.

\section{Pharma cologic a pproaches}

A significant number of patients with insomnia ben efit from pharmacologic therapy. Currently available hypnotic medications are benzodiazepine receptor agonists. These consist of benzodiazepines (temazepam, flurazepam, estazolam, and triazolam) and thenewer agents (zolpidem and zaleplon). 0 ther categories of medications used for alleviating insomnia are the sedating antidepressants and certain anticonvulsants. Trazodone is the most widely prescribed sedating antidepressant for insomnia. For patients with diabetic neuropathy, insomnia, and restless legs syndrome, anticonvulsants (such as gabapentin) may be useful.

\section{Behavioral management}

Behavioral approaches areimportant in the management of insomnia in diabetics. Adherenceto good sleep hygiene, sleep restriction, cognitivebehavioral therapy, and relaxation therapiesare effectiveand basic to thetreatment of insomnia. Behavioral interventionsaim to correct or removefactors that perpetuate or worsen insomnia ${ }^{16}$

Behavioral therapy alone or combined with pharmacologic treatments has been shown to be effective for primary as well as secondary insomnia. ${ }^{17,18}$ Traditional behavioral therapy requires multiple sessions for a period of 6-8 weeks. An abbreviated cognitive behavioral therapy of only two 25-minute sessions has been shown to be effective. ${ }^{19} \mathrm{~T}$ herefore, behavioral strategies should be an integral part of the management of insomnia.

\section{Condusion}

Sleep disturbances are common and can bedetrimental to thehealth, mood and quality of life of peoplewith diabetes. Sleep-disordered breathing, pain, restless legs syndrome, primary insomnia and lifestyle factors all contribute to a high rate of sleep complaints in this population. Because theetiologies of poor sleep quality is multifactorial, careful evaluation for insomnia, sleep-disordered breathing and restless legs syndromeshould bedone.

There is evidencethat treatment of sleep disorders such as sleep apnea, can improve glucose control and insulin sensitivity. Advances in behavioral therapy for insomnia, as well as improved safety and tolerability of the newer 
hypnotic agents and better control of neuropathic symptoms haveresulted in improvement in themanagement of sleep disruption in diabetics.

\section{References}

1. Skomro RP, Ludwig S, Salamon E, Kryger MH. Sleep complaints and restless legs syndrome in adult type 2 diabetics. Sleep Med. 2001;2:417-422.

2. Foley D, Ancoli-Israel S, Britz P, Walsh J. Sleep disturbances and chronic disease in older adults: results of the 2003 National Sleep Foundation Sleep in America Survey. J Psychosom Res. 2004;56:497-502.

3. Vigg A. Sleep in Type 2 diabetes. J Assoc Physicians India. 2003;51: 479-481.

4. Pillar G, Schuscheim G, Weiss R, et al. Interactions between hypoglycemia and sleep architecture in children with type 1 diabetes mellitus. J Pediatr. 2003;142:163-168.

5. Resnick HE, Redline S, Shahar E, et al. Diabetes and sleep disturbances: findings from the Sleep Heart Health Study. Diabetes Care. 2003;26:702-709.

6. Chasens ER, Weaver TE, U mlauf MG. Insulin resistance and obstructive sleep apnea: is increased sympathetic stimulation the link? Biol Res N urs. 2003;5:87-96.

7. Punjabi NM, Shahar E, Redline S, Gottlieb DJ, Givelber R, Resnick HE. Sleep-disordered breathing, glucose intolerance, and insulin resistance: the Sleep Heart Health Study. Am J Epidemiol. 2004;160:521-530.

8. Punjabi NM, Sorkin JD, Katzel LI, Goldberg AP, Schwartz $A R$, Smith PL. Sleep-disordered breathing and insulin resistance in middle-aged and overweight men. Am J Respir Crit Care Med. 2002;165:677-682.

9. Walters AS, Hickey K, Maltzman J, et al. A questionnaire study of 138 patients with restless legs syndrome: The 'Night-Walkers' survey. N eurology. 1996;46:92-95.
10. Zucconi M, Ferini-Strambi L. Epidemiology and clinical findings of restless legs syndrome. Sleep Med. 2004;5:293299.

11. Silbert PL. Diabetes mellitus, AIDS, and night sweats. Lancet. 1989;2:1285

12. Harsch IA, Schahin SP, Radespiel-Troger M, et al. Continuous positive airway pressure treatment rapidly improves insulin sensitivity in patients with obstructive sleep apnea syndrome. Am J Respir CritCare Med. 2004;169:156162.

13. Marchesini G, Pontiroli A, Salvioli G, et al. Snoring, hypertension and Type 2 diabetes in obesity. Protection by physical activity. J Endocrinol Invest. 2004;27:150-157.

14. Banarer S, Cryer PE. Sleep-related hypoglycemiaassociated autonomic failure in type 1 diabetes: reduced awakening from sleep during hypoglycemia. Diabetes. 2003;52:1195-1203

15. Goodnick PJ. Use of antidepressants in treatment of comorbid diabetes mellitus and depression as well as in diabetic neuropathy. Ann Clin Psychiatry. 2001;13:31-41.

16. Chesson AL J r, Anderson WM, Littner M, et al. Practice parameters for the nonpharmacologic treatment of chronic insomnia. An American Academy of Sleep Medicine report. Standards of Practice Committee of the American Academy of Sleep Medicine. Sleep. 1999;22:1128-1133.

17. Morin CM, Colecchi C, Stone J, Sood R, Brink D. Behavioral and pharmacological therapies for late-life insomnia: a randomized controlled trial. JAMA. 1999;281:991-999.

18. Edinger JD, Wohlgemuth WK, Radtke RA, Marsh GR, Q uillian RE. Cognitive behavioral therapy for treatment of chronic primary insomnia: a randomized controlled trial. JAMA. 2001;285:1856-1864.

19. Edinger JD, Sampson WS. A primary care "friendly" cognitive behavioral insomnia therapy. Sleep. 2003;26:177-182. 